\title{
CULTURA E EDUCAÇÃO NUM CONTEXTO ARTICULADOR DE MEDIAÇÕES PEDAGÓGICAS SIGNIFICATIVAS
}

\author{
Jefferson Correia da Conceição \\ Universidade do Estado da Bahia \\ jeffersoncorreia2@gmail.com
}

\begin{abstract}
Resumo
Este artigo apresenta algumas reflexões acerca das contribuições dos estudos sobre a Cultura e Educação articulados no contexto escolar. Tem como objetivo apresentar um panorama de discussões teóricas sobre Cultura e Educação a partir de diversos estudiosos do assunto, ao se analisar a literatura específica no que diz respeito ao histórico, objetivos, importância e atualidades acerca da temática cultural associada a educação. Optou-se pela utilização de pesquisa bibliográfica e, como instrumento de coleta de dados, um questionário aplicado aos estudantes. Os dados coletados apontaram que poucos estudantes percebem o fato cultural articulado com a educação, apesar de perceberem como algo relevante. Conforme os resultados obtidos, concluiu-se que, mediante os estudos sobre Cultura é possível dinamizar, motivar e envolver muito mais os educandos com as ações pedagógicas ofertadas pela unidade escolar abordada.
\end{abstract}

Palavras-chave: Educação. Aprendizagem. Cultura. Mediação.

\section{CULTURE AND EDUCATION IN A CONTEXT ARTICULATOR OF SIGNIFICANT PEDAGOGICAL MEDIATIONS}

\begin{abstract}
This article presents some reflections on the contributions of studies on Culture and Education articulated in the school context. It aims to present an overview of theoretical discussions on Culture and Education from various scholars of the subject, when analyzing the specific literature with regard to the history, objectives, importance and current news about the cultural theme associated with education. We chose to use bibliographic research and, as a data collection instrument, a questionnaire applied to students. The data collected pointed out that few students perceive the cultural fact linked to education, despite perceiving it as something relevant. According to the results obtained, it was concluded that, through studies on Culture, it is possible to stimulate, motivate and involve students much more with the pedagogical actions offered by the school unit addressed.
\end{abstract}

Keywords: Education. Learning. Culture. Mediation.

\section{CULTURA Y EDUCACIÓN EN UN ARTICULADOR DE CONTEXTO DE MEDIACIONES PEDAGÓGICAS SIGNIFICATIVAS}

\footnotetext{
Resumen

Este artículo presenta algunas reflexiones sobre las contribuciones de los estudios sobre Cultura y Educación articulados en el contexto escolar. Su objetivo es presentar una visión general de las discusiones teóricas sobre Cultura y Educación de varios académicos de la materia, al analizar la literatura específica con respecto a la historia, objetivos, importancia y noticias actuales sobre el tema cultural asociado con la educación. Elegimos utilizar la investigación bibliográfica y, como instrumento de recolección de datos, un cuestionario aplicado a los estudiantes. Los datos

Cidadania em Ação: Revista de Extensão e Cultura, Florianópolis (SC), v. 4, n. 1, jan./jun. 2020.
} 
recopilados señalaron que pocos estudiantes perciben el hecho cultural vinculado a la educación, a pesar de percibirlo como algo relevante. Según los resultados obtenidos, se concluyó que, a través de estudios sobre Cultura, es posible estimular, motivar e involucrar a los estudiantes mucho más con las acciones pedagógicas que ofrece la unidad escolar abordada

Palabras clave: Educación. Aprendizaje. Cultura. Mediación.

Cidadania em Ação: Revista de Extensão e Cultura, Florianópolis (SC), v. 4, n. 1, jan./jun. 2020. 


\section{INTRODUÇÃO}

Sabe-se que, desde o início da história da humanidade, a cultura sempre esteve presente em praticamente todas as formações sociais. O conhecimento da cultura pode abrir perspectivas para que o educando tenha uma compreensão do mundo no qual a dimensão simbólica esteja presente: a cultura ensina que é possível transformar continuamente a existência, que é preciso mudar referências a cada momento, ser flexível. Isto quer dizer que criar e conhecer são indissociáveis e a flexibilidade é condição essencial para aprender. Edgar Morin (2011, p. 56) coloca,

Cultura é o conjunto dos saberes, fazeres, regras, normas, proibições, estratégias, crenças, idéias, valores, mitos, que se transformam de geração em geração, se reproduz em cada indivíduo, controla a existência da sociedade e mantém a complexidade psicológica e social. Não há sociedade humana arcaica ou moderna, desprovida de cultura, mas cada cultura é singular.

Por isso, a considerar colocações de Morin (2011) a cultura ocupa um espaço considerável no cotidiano do homem, sobretudo na contemporaneidade. É através da cultura que se pode estabelecer a elaboração do conhecimento, possibilitando ao educando o crescimento progressivo em relação aos conhecimentos mediados.

Nesse viés, utilizar a cultura como forma de linguagem e comunicação pode ser também um instrumento eficaz no processo de produção de conhecimento dos educandos. O conhecimento mediado através da cultura, portanto, visa à criação de significações exercitando fundamentalmente a constante possibilidade de transformação do ser humano e isso fica bastante evidenciado também, na opinião de Saviani (2013, p. 27) quando diz,

Em suma, pela mediação da escola, dá-se a passagem do saber espontâneo ao saber sistematizado, da cultura popular à cultura erudita. Cumpre assinalar, também aqui, que se trata de um movimento dialético, isto é, a ação escolar permite que se acrescentem novas determinações que enriquecem as anteriores e estas, portanto, de forma alguma são excluídas.

Pelo exposto, convêm assinalar que, o acesso à cultura pode possibilitar a apropriação de novas formas culturais através das quais se podem expressar os próprios conteúdos dos saberes culturais. Cabe, pois, não perder de vista o caráter dos distintos saberes culturais, cuja primazia não pode ser destronada.

Deste modo, este estudo aborda a compreensão dos estudantes do $3^{\circ}$ ano do ensino médio do Centro Territorial de Educação Profissional do Litoral Norte e Agreste Baiano - 
CETEP-LN, na cidade de Alagoinhas - BA, sobre a cultura popular, de modo que, se possam estabelecer ligações com o conhecimento mediado pela escola e com a vida em geral, mediante o estudo da cultura enquanto tema transversal articulando-se com distintos campos de conhecimentos.

Como problema para a pesquisa destacou-se: em que medida a cultura popular da cidade de Alagoinhas pode ser um elo facilitador da aprendizagem? Tal problema tem como propósito determinar com maior especificidade as condições em que o fenômeno cultural ocorre e, se poderá estimular aprendizagens mediadas pela escola.

Várias pesquisas foram realizadas sobre o assunto, mas, acredita-se na possibilidade de novas verificações, indagando-se o grau de interferência dos fatores culturais e suas relações com a aprendizagem.

Com esse propósito, se podem mencionar pesquisas antecedentes com as duas abordagens - cultura popular e educação, que foram realizadas por: Philippe Perrenoud (2012), Demerval Saviani (2013), Maria Lúcia de Arruda Aranha (2014), Moema Toscano (2011), Carlos Rodrigues Brandão (2012) e Cipriano Carlos Luckesi (2013), dentre outros, que têm posições diversas sobre a cultura e a educação, pois se apresentam alicerçados em concepções que estimulam procedimentos reveladores de diversidades, para uma perspectiva mais crítica na exposição e interpretação dos dados acerca da cultura popular e da educação.

\section{A CULTURA E SUAS RELAÇÕES COM A APRENDIZAGEM CONCEITO DE CULTURA}

Quando se fala em cultura logo se pensa num estilo de vida de um povo, de uma sociedade, em seus costumes, em sua arte. A cultura é justamente o diferencial entre os povos, entre uma sociedade e outra e até mesmo entre um indivíduo e outro. As observações dos fenômenos culturais podem constituir uma síntese de elementos diversos, mas com uma estrutura singular, que poderá estar fornecendo o sentido e a identidade de uma sociedade ou grupo social, refletindo idéias e comportamentos, a complexidade das relações interpessoais e, talvez, fusões e mobilidades no grupo. Nesse sentido, é conveniente citar o que é esclarecido por Azevedo (2014, p. 167), quando ressalta a cultura, mobilidade, trocas e interpenetrações sócio-culturais e enfatiza, Cidadania em Ação: Revista de Extensão e Cultura, Florianópolis (SC), v. 4, n. 1, jan./jun. 2020. 
Intensificando a mobilidade social ou, por outras palavras, a migração de pessoas, como de idéias e de traços culturais, de um grupo ou de uma classe social para outra, e elevando ao poder "homens novos", nem sempre com idéias firmes, mas com menos compromissos, trouxe, entre outras conseqüências, uma rápida mudança social, a desintegração dos costumes tradicionais do velho padrão cultural e maior complexidade nas relações sociais; e, rompendo as linhas da clivagem social entre os vários grupo e classes, contribuiu poderosamente não só para uma "democratização" mais profunda como também para uma intensidade maior de trocas econômicas e sociais.

Azevedo (2014) ainda na página 167 que,

As idéias novas, já em circulação, difundiram-se com mais rapidez quer pelo impulso que lhes deu a própria mobilidade social, favorecida pela revolução e por suas conseqüências, quer pela demora na elaboração dos princípios fundamentais de uma nova política nacional de cultura, entrando em contatos freqüentes que facilitavam tanto as fusões e interpenetrações, como os conflitos de cultura e tendências diversas.

Por isso, pode-se entender que a história cultural é o ramo da história que se dedica ao estudo da cultura humana, do conhecimento humano, dos processos desenvolvidos pelo homem para modificar o meio natural, o meio em que vivemos e os costumes que são desenvolvidos, são conservados e transmitidos de geração em geração. As diferenças que existem entre as diversas culturas no mundo e as relações existentes entre elas é o que buscamos conhecer e muitas vezes absorver ou simplesmente observar.

Sobre essa questão, Machado (2012, p. 83) pontua,

[...] Assim, na longa caminhada da humanidade o homem fez de si próprio as mais diversas representações, dependendo das situações e dificuldades enfrentadas na luta pela sobrevivência e na tentativa de explicar o mundo que o cerca. Mesmo que não se apresente claramente, há um conceito de homem subjacente a cada comportamento. Certamente, o conceito do que é ser homem varia de cultura para cultura.

Nesse sentido, Toscano (2011, p. 30) defende que,

A cultura pode, pois, ser definida como o resultado de todo o esforço do homem através dos tempos, feito no sentido de dominar a natureza e pô-la a seu serviço.

Cidadania em Ação: Revista de Extensão e Cultura, Florianópolis (SC), v. 4, n. 1, jan./jun. 2020. 


\begin{abstract}
Assim, é cultural tudo o que não é natural, isto é, tudo que sofreu de alguma forma a influência transformadora do homem. Por exemplo, uma pedra é por definição, um objeto que se pode classificar como natural, isto é, que nos é dado pela natureza. Porém, desde que o homem dela se aproprie, e, a fim de melhorar sua eficácia, imprima nela qualquer marca humana (adoce suas arestas, aguce uma das suas extremidades, modele uma empunhadura), já temos um instrumento adaptado pelo homem para outros fins que não aqueles para os quais o objeto existe, logo temos uma criação cultural.
\end{abstract}

Dessa forma, pode-se compreender que na cultura estão inscritas as vontades mais puras e duradouras do coração dos homens. A história da cultura e da sociedade repousa em grande parte nas evoluções culturais, pois a vontade de um povo se manifesta em variadas formas. Quando uma civilização desaparece, no imenso decorrer dos tempos, não somente nas pedras dos edifícios desmantelados é que se vão encontrar os marcos dessa cultura e, nas diferenciações dessas pedras na maneira de erguê-las ou agrupá-las é que estão as diferenças dos povos e das culturas.

\title{
CULTURA POPULAR E CULTURA ERUDITA
}

Para compreender qualquer cultura, deve-se percebê-la como algo singular, com vida própria, dinâmica, plena e representativa; enfim, como algo genuíno e integrado a vida das pessoas. Aranha (2014, p.40) sobre a questão coloca,

\footnotetext{
[...] quando contrapomos, por exemplo, cultura de elite e cultura popular, já estamos emitindo juízos de valor: a cultura de elite seria superior porque refinada, elaborada, ao passo que a cultura popular seria inferior por se tratar de expressão ingênua e não-intelectualizada. Outra confusão está em se identificar cultura de elite (que na verdade é a cultura erudita) com produção da classe dominante. De maneira geral, isso se deve ao pressuposto de que a verdadeira cultura é a produzida pela elite. [...] quando se fala de conhecimento, despreza-se o saber popular para se valorizar apenas a ciência; ao se tratar da técnica, exaltase a mais refinada tecnologia; ao se referir à arte contemporânea, pensa-se nas pinturas de Picasso; e, quando se volta a atenção para a arte popular, é para considerá-la de forma depreciativa, como arte menor ou produção exótica e objeto de curiosidade.
}

Neste sentido, pode-se afirmar que o fato cultural é imemorial e, como cultura empírica, surgiu quando o homem tentou resolver e compreender as dificuldades e facilidades do seu habitat relacionadas com a sobrevivência, subsistência e perpetuação da espécie. Sabe-se que a cultura se mantém no universo, num processo de adequação, de flexibilidade, quando pressões externas ou internas atuam e impõem modificações.

Entende-se que, dependente de um condicionamento social é objeto de Cidadania em Ação: Revista de Extensão e Cultura, Florianópolis (SC), v. 4, n. 1, jan./jun. 2020. 
interferência, reconstituição, aniquilamento, às quais responde pacífica ou resistentemente. Da cultura popular saíram as elaborações manifestadas que, em condições outras, atingiram fins outros, construindo o lastro da cultura erudita por perceber-se que esta se apropria de alguns valores da cultura popular para fazer valer os seus intentos (SAVIANI, 2013).

De acordo com M. Ayala (2015, p. 51), a cultura popular tanto veicula os pontos de vista e interesses das classes subalternas, numa perspectiva de crítica à dominação, mais ou menos consciente, quanto internaliza os pontos de vista e interesses das classes dominantes, legitimando a desigualdade existente.

Entre a cultura popular e a erudita há modelos intermediários, porosos e mutáveis. Os próprios limites da cultura popular e da erudita não se caracterizam pela impermeabilidade, ao contrário, da fricção contínua entre uma e outra, observam-se os fenômenos da descensão, quando complexos culturais eruditos são absorvidos pelo povo e de ascensão, quando os complexos culturais do meio popular são absorvidos pelos eruditos (AYALA, 2015, p. 88).

A cultura popular difere da cultura erudita por ser produzida por aqueles mesmos que a consomem. Constitui-se numa produção elaborada pelo próprio grupo, caracterizando assim o valor de uso da cultura. Estabelecem questionamentos, recusas, contestações às normas e valores estabelecidos. É extremamente útil em seu papel de fixação e auto-reconhecimento do indivíduo dentro do grupo (COELHO, 2014).

Diante disso, pode-se perceber que a cultura erudita, constitui-se de todos os produtos e manifestações canonizadas pela crítica erudita. Valoriza o que está assegurada pela aceitação das classes sociais favorecidas. Ela pode ser entendida como sistema específico que, articulando a outros, forma o que se pode denominar, em consonância com os meios formais, uma cultura apoiada no sistema dominante.

\section{CULTURA E CULTURA DE MASSA}

Os seres humanos devem seu predomínio atual, em parte a sua capacidade mental, mas ainda mais às suas idéias, hábitos e técnicas que foram transmitidos pelos ancestrais. Tendo nascido numa sociedade qualquer, o ser humano descobre que a maioria dos problemas que se apresentam durante sua vida foram já foram enfrentados e resolvidos pelos que lhe antecederam. Cabe-lhe apenas aprender as soluções. Se conseguir fazer este Cidadania em Ação: Revista de Extensão e Cultura, Florianópolis (SC), v. 4, n. 1, jan./jun. 2020. 
aprendizado com êxito, não terá necessidade de muita especulação.

Por esse caminho, percebe-se que a cultura de massa está fortemente vinculada ao fenômeno do consumo, sendo que o momento de propagação dessa cultura ocorre por interferência decisiva dos meios de comunicação. Constitui-se numa cultura elaborada para amplo público, destilando esquemas simplificadores e caracterizada pelo fato de não ser feita por aqueles que o consomem. É fortemente influenciada e alimentada por uma economia baseada no consumo de bens, numa economia de mercado (COELHO, 2014).

É uma cultura impulsionada pela sociedade de consumo que aliena e reduz a capacidade de autocrítica, assim como da sociedade como um todo. No entanto, também é dotada de força e motivação em sua banalidade, responsável por um dinamismo capaz de fazê-la romper barreiras de classes sociais e culturais, colocando em comum algumas manifestações que outrora eram características de outras camadas sociais (COELHO, 2014).

Poderá também, beneficiar o desenvolvimento do homem, em virtude da sua própria dinâmica interior, permitindo um domínio mais rápido das concepções de mundo, uma vez que, o acúmulo de informação poderá transformar-se em formação, pois, a quantidade poderá provocar alterações na qualidade (COELHO, 2014).

Assim, pode-se perceber que o rumo e a velocidade das transformações do mundo moderno exigem cada vez mais, de todos os homens, uma constante verificação dos conhecimentos adquiridos e uma contínua readaptação a um mundo que, afinal, é dinâmico e mutável, sendo, portanto, parte do contexto educacional.

\section{CULTURA E AS ÁREAS DE CONHECIMENTOS}

A adoção da cultura como veículo motivador da aprendizagem, consiste no aproveitamento de conhecimentos variados, para diversos campos ou áreas de conhecimento, com objetivos definidos. A Medicina poderá aproveitá-la como terapia ocupacional e no processo de reabilitação física, geriátrica, traumática e de ajustamento da personalidade. A economia poderá tornar viável a valorização real do artesanato, integrando, pela valorização, a mão-de-obra artesanal, dentro do complexo da mão-de-obra nacional.

A Educação, dela poderá servir-se, quer no nível universitário, para a formação 
teórico-prática de elementos que se destinam às pesquisas culturais (em geral ou em áreas especializadas), quer no ensino fundamental ou médio, para enriquecimento do conteúdo programático e sua adequação à realidade. Em um e outro caso, deve a metodologia estar de acordo com os princípios sociais, que valorizam o homem, o ser e não apenas o ter (BRANDÃO, 2012).

Entende-se também, que é da competência do setor educacional trabalhar em vários planos e linhas de ação, incluindo a cultura popular tradicional nas disciplinas ou campos de conhecimentos educativos, ao mesmo tempo contando com a colaboração dos que portam essa cultura, como artesãos, dançadores, instrumentistas e cantadores dentre outros.

A cultura na escola não é apenas o ensino de conhecimentos sistematizados que dizem respeito à ordem de algum fenômeno ou manifestação cultural aos adolescentes e crianças ou adultos, mas sim, a sua adoção ou aproveitamento como fator didático, onde houver oportunidade e onde favorecer a compreensão e o desenvolvimento da memória cultural, oferecendo um centro de interesses com o que se está transmitindo.

A primeira exigência para a boa aplicação é o conhecimento que o docente mediador deve ter das manifestações e fenômenos culturais, razão pela qual tanto se tem insistido na inclusão do conteúdo cultural, nas escolas de formação de professores, com uma metodologia que enalteça os fenômenos da cultura popular, assim como, o processo ensino-aprendizagem. Isso requer uma contribuição efetiva por parte dos envolvidos no processo, para que tais conteúdos não fiquem restritos sazonalmente em agosto considerado como o mês do folclore (CARVALHO NETO, 2013).

O conhecimento é imprescindível para saber o que é cultura a fim de poder classificá-la como cultura popular autêntica, cultura popular aplicada, projeção de cultura popular, cultura erudita e cultura de massa. Uma dança folclórica é cultura popular autêntica quando executada pelo grupo que a guarda em seu contexto cultural. Executada por alunos de um estabelecimento, respeitado o modelo folclórico, é cultura popular aplicada.

Apresentada em teatro por profissionais, modificada num ou noutro ponto para satisfação estética de uma determinada clientela, é projeção da cultura popular. A projeção da cultura popular se verifica nos setores culturais, atingindo a obra de diversos autores, quando se apropriam do conhecimento do povo para produzir seus trabalhos nas mais diversas linguagens: música, pintura, literatura, escultura, teatro, cinema, balé e etc. Cidadania em Ação: Revista de Extensão e Cultura, Florianópolis (SC), v. 4, n. 1, jan./jun. 2020. 
(CARVALHO NETO, 2013).

A cultura na escola está condicionada ao grau de ensino a que se destina. Entendese a cultura popular como formação (material didático que ajusta a integração da personalidade) e informação (fonte de conhecimento e de enriquecimento intelectual). Como formação é seletiva, pois o ensino, como critério formativo, é dirigido a crianças e adolescentes ou adultos - EJA, na etapa chamada de formação, correspondendo ao Ensino Fundamental.

Objetiva a consecução de finalidades éticas, estéticas, sociais, históricas, políticas, econômicas etc. Como informação, o objetivo imediato é a apresentação do fato pelo fato, como um conhecimento novo, servindo-se de uma técnica descritiva, auxiliada por audiovisuais. Como formação, é a cultura popular um meio; como informação, é um fim (CARVALHO NETO, 2013).

A utilização da cultura se condiciona, igualmente, a um critério seletivo do fato a ser aplicado, cabendo ao professor mediador partir do princípio de que o objetivo da utilização da cultura está em traçar um perfil aproveitando os elementos que, vindos do povo, podem servir para melhor conhecê-lo ou torná-lo conhecido, situando-o na realidade brasileira, além de favorecer essa percepção aos educandos.

Nessa perspectiva, os Parâmetros Curriculares Nacionais (PCN), propostos pelo Ministério de Educação e do Desporto, propõem como um dos temas transversais a pluralidade cultural. Assim, nos Parâmetros Curriculares Nacionais PCN-ARTE (1997, pp. 113-114) percebe-se a seguinte inclusão: “Tratar da diversidade cultural brasileira, reconhecendo-a e valorizando-a, e da superação das discriminações aqui existentes é atuar sobre um dos mecanismos de exclusão, tarefa necessária, ainda que insuficiente, para caminhar na direção de uma sociedade mais democrática".

Entendendo-se as citações anteriores, pode-se perceber como os estudos culturais poderão contribuir, nos diversos campos ou áreas de conhecimentos. No setor de Expressão e Comunicação/Lingua Portuguesa, a literatura oral integra-se totalmente, atendendo o cultivo da língua na forma oral e escrita, na morfologia, na forma de expressão, permitindo observar os elementos da prosa e da poesia; poderá desenvolver o sentido de crítica, poderá dimensionar os valores humanos, poderá estimular os impulsos para o belo, o bom e o nobre ao transportar noções de moral, ética e estética, poderão colaborar no domínio da manifestação verbal e na elaboração do pensamento com ordem e Cidadania em Ação: Revista de Extensão e Cultura, Florianópolis (SC), v. 4, n. 1, jan./jun. 2020. 
seqüência lógica, além de permitir o entendimento dos variados modos de comunicação e expressão do nosso país e do mundo.

Convêm destacar nos Parâmetros Curriculares Nacionais PCN-ARTE (1997, pp.

118-119) as seguintes expressões:

$\mathrm{Na}$ prática, os projetos podem envolver ações entre disciplinas, como, por exemplo, Língua Portuguesa e Arte, ou Matemática e Arte e assim por diante. Os conteúdos dos temas transversais também são favoráveis para o trabalho. Os projetos devem buscar nexos na seleção dos conteúdos.

O mesmo documento na página 114 esclarece: “Com relação ao tema Pluralidade Cultural, por exemplo, o professor poderá investigar como integrá-lo na apreciação estética dos alunos, buscando maneiras de estudar as manifestações artísticas como exemplos de diversidade cultural".

Nas Ciências Sociais, noções de História podem ser transmitidas por meio de contos, lendas, provérbios, trovas, literatura de cordel etc. A lenda e a poesia histórica brotam da imaginativa popular, registrando o acontecimento e perpetuando o herói; relatam as tradições de vários ciclos da civilização, esclarecem o processo da fundação das cidades, falam das antigas gentes e costumes (BRANDÃO, 2012).

É o outro lado da história. Consideramos a história e a cultura popular os dois pólos da humanidade. Aquela é o passado escrito. Esta outra é o que não foi escrito, mas se perpetuou na tradição. A cultura poderá ser incorporada aos estudos históricos como fonte indispensável para a análise total da cultura.

Assim surgiu a História cultural, que só pode ser reconstituída graças, em parte, à contribuição dos fatos folclóricos na caracterização das áreas de cultura quer no tempo, quer no espaço (BRANDÃO, 2012).

$\mathrm{Na}$ Geografia humana, os tipos brasileiros regionais (baiano, gaúcho, vaqueiro, tropeiro, jangadeiro etc.) e na Geografia física (praias, sertões, grutas, lagos, montanhas, zonas do pastoreio, da mineração, da agricultura etc.) podem ser explicadas pela literatura oral.

Como auxiliar da Matemática, jogos, brinquedos infantis, adivinhas, estórias, trava línguas ${ }^{1}$ conduzem ao aprendizado dos valores matemáticos e à solução de problemas. A estória e contos, podem funcionar como centro de interesse, permitindo sugestões para a idéia de par, conhecimento das horas, dúzia e meia-dúzia, dezena e centena, metro, Cidadania em Ação: Revista de Extensão e Cultura, Florianópolis (SC), v. 4, n. 1, jan./jun. 2020. 
decímetro, formas geométricas, além de contribuir para melhoria da interpretação e compreensão do mundo. A estória faz o raciocínio partir de uma simples unidade e atingir uma grandeza imensurável. Uma infinidade de publicações, algumas de caráter popular, outras de escritores especializados, apresenta curiosidades matemáticas baseadas na cultura popular (BRANDÃO, 2012).

Nas Ciências Biológicas, os provérbios meteorológicos, o mitológico e o lendário dos astros, das origens da água, da terra, do fogo, do raio e do ar, do dia e da noite são medidas comparativas entre o conhecimento empírico e o científico; plantas e animais estão nas lendas, que explicam a razão de serem como são e de fazerem o que fazem.

A leitura da natureza nasceu com o homem que planta e, porque deseja colher, interpreta as nuvens e os ventos, os céus e os ares. É uma leitura coberta, a ser decifrada antes de planejamentos na área da agricultura. $\mathrm{O}$ agrônomo dá as sementes, mas o lavrador só vai plantá-las quando achar que a lua está propícia. Uma cerca precisa ser feita para vedar a plantação, mas a madeira, a Candeia, só será cortada quando chegar a lua "que não dá bicho" (BRANDÃO, 2012, p. 404-405 ).

Os provérbios ligados às doenças e à medicina (preventiva ou curativa) merecem consideração porque orientam e alertam. É o capítulo de valorização da medicina popular, baseada no aproveitamento das propriedades terapêuticas dos vegetais.

O lastro das Artes Visuais ou Plásticas repousa sobre vários tipos de artesanato, de artes populares, de instrumentos musicais folclóricos que podem compor inúmeras atividades, sobre o canto, as danças e os folguedos populares. Estas expressões resultam da

\footnotetext{
${ }^{1}$ Disposição lingüística, em prosa ou verso, caracterizada de forma ordenada, que se torna extremamente difícil e, às vezes, quase impossível, pronunciá-la sem tropeços. Podem agrupar múltiplas espécies do folclore narrativo, do folclore poético e do folclore lingüístico. Rima criativa, em versos. (FERREIRA, 1999, p.1994)
} 
ambientação do homem ao meio, da satisfação de suas necessidades materiais e espirituais e traçam seu perfil sócio - econômico - cultural (PCN-ARTE, 1997).

\section{METODOLOGIA, PÚBLICO ALVO E LOCAL DA PESQUISA}

A delimitação dos sujeitos da pesquisa ocorreu em face da necessidade de se estudar parte de um universo local, visto que a pesquisa tem por propósito generalizar os resultados coletados, para a população da qual os sujeitos pesquisados constituem uma amostra.

Para tanto, adotou-se pesquisa randômica (SOARES, FARIAS; CESAR, 1991) que orienta uma distribuição aleatória intencional dos instrumentos, contudo, com moderado controle em face dos objetivos do trabalho, sem comprometer a intencionalidade quantitativa e qualitativa da coleta de dados, com o apoio de formulários estruturados e semi - estruturados, para permitir a cada um dos educandos participantes iguais chances de serem selecionados, para compor um grupo de 60 (sessenta) estudantes do $3^{\circ}$ ano do ensino médio, correspondendo a 50\% de um total de 123 (cento e vinte três) discentes da série mencionada no turno vespertino.

Os formulários foram aplicados durante um período de 03 (três) semanas, em dias alternados e distintos, utilizando-se no total quatro turnos em horários variados e disponibilizados pela gestão escolar, previamente agendado com as séries, no turno vespertino, para não comprometer o andamento das atividades docentes na unidade escolar.

Vale ressaltar, que em um dos turnos utilizados para pesquisa, foi possível ter acesso a uma sala de aula num horário vago, em virtude da ausência de um dos docentes por motivos de saúde. Nos demais momentos, foi possível contar, voluntariamente, com a colaboração do docente que se encontrava na sala de aula. Cada formulário precisou em média de 25 minutos para preenchimento, por parte dos estudantes.

O propósito foi efetivar pesquisa qualitativa, sobre o grau de interferência da Cultura Popular no aprendizado dos educandos, querendo com isso, perceber-se a realidade social que é mais rica que qualquer teoria, qualquer pensamento e qualquer discurso que se possa elaborar sobre ela.

No turno citado foram verificadas quatro turmas do $3^{\circ}$ ano do Ensino Médio, tendo Cidadania em Ação: Revista de Extensão e Cultura, Florianópolis (SC), v. 4, n. 1, jan./jun. 2020. 
em cada uma delas em torno de 30 (trinta) educandos, sendo 87 (oitenta e sete) do sexo feminino e 33 (trinta e três) do sexo masculino. A faixa etária dos participantes da pesquisa dos 17 aos 21 anos, oriundos das áreas urbana e rural do município.

A delimitação do ambiente aconteceu em razão do Centro Territorial ser o espaço natural de encontro dos participantes da pesquisa e, por isso, o CETEP-LN, foi escolhido por ser representativo na cidade, ser uma escola pública estadual de tradição no município, pelos serviços prestados à comunidade ao longo de anos e pelos efeitos e impactos positivos na comunidade, que podem ser verificados mediante os distintos profissionais oriundos da unidade escolar, ou seja, ex-estudantes, que atuam não somente na cidade de Alagoinhas - BA, mas também no entorno social.

Convém esclarecer, que nesse tipo de abordagem, encontram-se caminhos para buscar aprofundamentos das discussões no que se refere às variadas conduções de estudos, cujos participantes se articulam e se envolvem ativamente com o trabalho proposto, não somente como depoentes ou apenas “[...] como produto descartável de valor meramente utilitário [...]" (MACEDO, 2004, p. 30).

Do ponto de vista da mediação das atividades, a referência foi a dialogicidade, com distintos procedimentos metodológicos conforme os encontros que foram vivenciados por intermédio da realização sistemática de "rodas de conversas" para esclarecimentos conforme as necessidades.

Assim, surgiram propostas, diálogos, esclarecimentos, dúvidas e motivações que nos ajudaram a definir e refletir sobre os caminhos, os métodos, as razões do trabalho em andamento, pois se pensou na riqueza de articulações das atividades pensadas sobre a cultura e educação matemática enquanto bases para estudos articulares, também como pesquisa e como trabalho pedagógico fecundo para a formação dos estudantes. É de fato, um processo que facilita o relacionamento entre os integrantes e supera desafios metodológicos porventura existentes.

\section{DESENVOLVIMENTO E DISCUSSÃO}

Se a cultura for abordada dialeticamente no contexto escolar, poderá ser realmente estimuladora para o desenvolvimento do conhecimento com educandos motivados, dispostos, aptos e integrais, sendo assim de relevância para abordagem, entendimento e ampliação das ações pedagógicas, que contemplem as diversidades culturais conjugadas Cidadania em Ação: Revista de Extensão e Cultura, Florianópolis (SC), v. 4, n. 1, jan./jun. 2020. 
com distintas áreas de conhecimentos no ambiente escolar.

Para se aprofundar mais no assunto, foi preciso ressaltar algumas indagações: terá a Cultura Popular influência na percepção dos educandos, com vistas ao processo ensinoaprendizagem? As manifestações da Cultura Popular poderão contribuir para absorção do conhecimento dos educandos do $3^{\circ}$ ano de ensino médio?

Desta forma, o objetivo geral deste trabalho é verificar a influência da Cultura Popular no conhecimento e no processo de aprendizagem dos educandos mencionados, com a intenção de estimular discussões, observações e o entendimento sobre a Cultura Popular, verificando-se os elementos mais simples e os mais complexos, dos eventos da cidade, permitindo-lhes que estabelecessem um contato mais direto com as dimensões do meio imediato, averiguando a produção individual e coletiva, tendo acesso a diferentes trabalhos ligados às manifestações populares da cidade, percebendo os elementos que permeiam as produções culturais locais.

Mediante esses objetivos, procurou-se estabelecer algumas hipóteses:

- A Cultura Popular influencia no processo ensino-aprendizagem dos educandos do $3^{\circ}$ ano do Ensino Médio;

- A Cultura Popular contribui no processo ensino-aprendizagem dos educandos do $3^{\circ}$ ano do Ensino Médio;

- Numa sociedade contextualizada pelo multiculturalismo, a Cultura Popular é desvalorizada pelos educandos do $3^{\circ}$ ano;

- $\quad$ Os educandos do $3^{\circ}$ ano do Ensino Médio têm percebido as manifestações da Cultura Popular como veículo facilitador da aprendizagem.

Diante da subjetividade do tema, o estudo foi feito por meio de uma abordagem qualitativa e quantitativa de pesquisa, utilizando recursos de pesquisa bibliográfica e pesquisa documental (Projeto Escolar, gravuras, pinturas e fotografias antigas da cidade, fragmentos de documentários filmados com algumas manifestações culturais da localidade, objetos antigos e o patrimônio arquitetônico da cidade), seguida de coleta de dados em pesquisa de campo, tendo como envolvidos diretamente na investigação, os educandos mencionados, com a intenção de apoiar os princípios teóricos apresentados durante a elaboração dos trabalhos. Assim, trata-se de um estudo, realizado também, a partir de algumas observações feitas na cidade de algumas expressões artísticas e culturais, para Cidadania em Ação: Revista de Extensão e Cultura, Florianópolis (SC), v. 4, n. 1, jan./jun. 2020. 
aprofundar o trabalho dissertativo.

Com a finalidade de perceber dados mais significativos do fenômeno abordado, este trabalho teve por finalidade discutir conceitos de cultura popular de massa e erudita, estabelecendo-se relações com a aprendizagem; discutir o papel da escola e do docente mediador, sob a égide dos temas transversais, numa abordagem reflexiva; expor aspectos históricos da cultura brasileira, com a intenção de compreender-se num contexto mais amplo a cultura popular local; apresentar alguns resultados analisando-se e discutindo-se os dados coletados e discutir propostas metodológicas alternativas para a mediação e valorização da Cultura Popular, por meio da arte, da interdisciplinaridade, dos eixos e temas transversais.

Não se tem a pretensão de esgotar o tema, pois essa abordagem é uma das possibilidades de pesquisa em busca de caminhos para ampliação do conhecimento, entendendo e conhecendo aspectos do trato pedagógico por intermédio da Cultura Popular.

\section{CONSIDERAÇÕES FINAIS}

Ficou evidente, através das informações colhidas dos educandos participantes da pesquisa, que a Cultura Popular é um canal importante na vida das pessoas, pois através dela pode-se veicular uma série de emoções, desejos e insatisfações e quanto maior o envolvimento das pessoas, melhor será a representatividade, requerendo para isso, mais ênfase na adoção e tratamento do assunto, sobretudo diante da contemporaneidade.

Tiveram-se também, condições de perceber, que Arte e Cultura Popular formam um todo coeso, uma vez que, existe certa dependência entre ambas, na maneira de serem concebidas, apresentadas e perpetuadas, sem falar nos motivos em comum que lhes dão origem, ou seja, a criatividade, a emoção e a intenção. Percebeu-se também, que diante do pluralismo conceitual da sociedade contemporânea que os estudantes entendem o que é Cultura Popular, mas não a vivenciam numa intensidade que poderiam, em virtude dos apelos da Cultura de Massa, comprometendo assim, a visibilidade das manifestações populares, apesar de perceberem-na como veículo que poderia estar facilitando a aprendizagem na instituição escolar.

Partindo-se destas compreensões e apoiando-se na pesquisa realizada conclui-se 
que:

- A Cultura Popular poderia ser incluída no currículo através de metodologia qu valorize a adoção de projetos;

- O caráter e a natureza interdisciplinar da Cultura Popular são essenciais para uma escola que pretende se manter viva;

- A valorização e ênfaese do conhecimento popular local são fundamentais para caracterização da escola e da sociedade na qual está inserida;

- Não há uma efetiva valorização da Cultura Popular na série pesquisada na unidade escolar;

- Ausência de ênfase da Cultura Popular na série pesquisada na escola na estimula o interese dos alunos por alguns estudos formais, em virtude da dissociação com a realidade imediata.

Algumas abordagens sobre a cultura apoiadas em metodologias adequadas e dialogadas entre os mediadores das distintas áreas de conhecimentos, poderiam conferir ao currículo uma perspectiva de totalidade, respeitando-se as especificidades epistemológicas das respectivas áreas de conhecimento.

Propõe-se a organização dos planos de estudo de forma interdisciplinar, sugerindose que o processo pedagógico tenha como base: o trabalho sistematizado com leituras de publicações diversas; a produção própria e coletiva dos textos e manifestações culturais; a utilização intensa da Biblioteca, dos audiovisuais, das inúmeras mídias sociais com propósitos específicos e o uso de diversos recursos pedagógicos disponíveis na escola.

Propõe-se também, a exploração de recursos externos à escola (os Cinemas, os Teatros, os Museus, as Exposições e etc.); a investigação de problemas de ordem sócioeconômica, do ponto de vista histórico-cultural, geográfico, sociológico, filosófico e político; a realização de atividades práticas (laboratórios e visitas de campo); o uso de acervos e patrimônios histórico-culturais da região, a bem dos estudos culturais articulados convenientemente com as unidades de ensino no contexto escolar abordado. 


\section{REFERÊNCIAS}

ARANHA, M. L. de A. Filosofia da Educação. São Paulo: Moderna, 2014.

AYAlA, M.; AYALA; M. I. N. Cultura Popular no Brasil. São Paulo: Ática, 2015.

AZEVEDO, F. de. A transmissão da cultura. 5. ed. São Paulo: Melhoramentos, 2014.

BRANDÃO, C. R. A educação como cultura. São Paulo: Brasiliense, 2012.

CARVALHO NETO, P. de. Folclore e educação. Rio de Janeiro: Forense, 2013.

COELHO, T. O que é indústria cultural. São Paulo: Brasiliense, 2014.

FERREIRA, A. B. de H. Novo Aurélio século XXI: O dicionário da língua portuguesa.

8.ed. Rio de Janeiro: Nova Fronteira, 1999.

LUCKESI, C. C. Filosofia da Educação. São Paulo: Cortez, 2013.

MACEDO, R. S. Métodos em pesquisa: diário de campo: notas de existência e conhecimento. In: MACEDO, Roberto Sidnei. A etnopesquisa crítica e multirreferencial nas Ciências Humanas e na Educação. 2. ed. Salvador: Edufba, 2004.

MACHADO, C. G. Multiculturalismo: Muito além da riqueza e da diferença. Rio de Janeiro: DPSA, 2012.

MORIN, E. O método (parte 1). São Paulo: Sulina, 2011, p. 56-115.

PARÂMETROS CURRICULARES NACIONAIS - ARTE. SECRETARIA DE EDUCAÇÃO FUNDAMENTAL. Brasília: MEC/SEF, 1997.

PERRENOUD, P. Pedagogia diferenciada: das intenções à ação. Trad. Patrícia Ciattoni Cidadania em Ação: Revista de Extensão e Cultura, Florianópolis (SC), v. 4, n. 1, jan./jun. 2020. 
Ramos. Porto Alegre: Arte Médicas Sul, 2012.

SAVIANI, D. Educação: Do senso comum a Consciência Filosófica. 13. ed. Campinas, São Paulo: Editora Autores Associados, 2013.

SOARES, J. F.; FARIAS, A. A.; CESAR, C.C. - Introdução à Estatística. Rio de Janeiro, Ed. Guanabara Koogan S.A., 1991.

TOSCANO, M. Introdução à sociologia educacional. São Paulo: Àtica, 2011. 